\title{
Visual Democratisation: AR and the Underpass Festival
}

\author{
Christian Tilt \\ Etic Lab \\ Frolic House, 23 Frolic Street, \\ Newtown, Powys, SY16 1AP, Wales \\ chris@eticlab.co.uk
}

\author{
Stephanie Moran \\ Etic Lab \\ Frolic House, 23 Frolic Street, \\ Newtown, Powys, SY16 1AP, Wales \\ stephanie@eticlab.co.uk
}

\author{
Alexander Hogan \\ Etic Lab \\ Frolic House, 23 Frolic Street, \\ Newtown, Powys, SY16 1AP, Wales \\ alex@eticlab.co.uk
}

\begin{abstract}
This paper discusses the opportunities Augmented Reality (AR) offers art experiences to merge underused public spaces with cultural programming, establish communities, and influence urban development. It focuses on the issues of usability and accessibility necessary for the democratisation of the technology and uses Etic Lab's current project in development, The Underpass Festival, as a model for speculatively testing these ideas. This structure exemplifies Etic Lab's bottom-up approach to R\&D that aims to align emerging technologies with issues surrounding social and cultural development. The Underpass Festival in Milton Keynes will constitute a study taking cues from groups of artists, the local community and publicly available data to propagate the use of AR in the built environment. It is scheduled to take place in Summer 2020. Our research currently extends to an on-going feasibility study to establish a route to 'hanging' artworks on the walls of public walkways. The festival aims to transform Milton Keynes' iconic but underappreciated public spaces into the cultural real estate they were designed to be, and to develop a radical new democratic model for the role of art and galleries across the city, navigating the, "digital representations that reconfigure everyday experiences of place" (Feldman 2018), with little to no 'visible' footprint. We believe that software-based AR, the kind contingent on the existing technology people already carry around, should focus on accessible spaces repurposed as virtual sites for augmented reality implementation. It is our understanding that the suspension of disbelief that augmented and virtual reality play with is not limited to high definition visuality, and that the fidelity of the 'reality' presented should not be at the expense of its immediacy, accessibility and usefulness. These characteristics, for us, are the crux of visual democratisation and the basis of our research. Our feasibility study is, therefore, looking to the limitations of the existing technology available to the average member of the public: not as a route to developing the AR assets themselves, but instead as a means for the city and its inhabitants to begin mapping and reclaiming these particular sites. This paper will examine the issues of usability and democratisation of $A R$ technology in relation to the Underpass Festival, and to what constitutes visual democratisation in the context of AR development. It will discuss the festival as speculative case study and work in progress, and its site-specificity. It will use the challenge of displaying artworks virtually in public spaces to consider the importance of visual quality relative to other attributes such as accurate mapping and 'hanging' on the underpass walls. It will conclude by comparing this project with some previous Etic Lab research around what we call the Oz Effect, and the impact of revealing 'the man behind the curtain', or the workings of the technology. It will examine this in relation to the aesthetics of the 'poor image'.
\end{abstract}

\section{Augmented reality. Smart cities. Democratising technology. Art festivals.}

\section{AUGMENTED REALITY AND CULTURAL PROGRAMMING IN PUBLIC SPACES}

As the way we integrate technology into our lifestyles matures, so too does the politicisation of technology's constraints. Iterations of hardware and multiple software solutions previously accepted as wholly beneficial and outwardly progressive have distilled into a growing public awareness of market operations (Barrington 2018) that have at least altered, if not slightly soured the next wave of digital innovation in the eyes of users. With household names and industry leaders already shifting position to counteract the pushback from consumers and government reacting to platforms' and handsets' infiltration of privacy and lack of transparency (Vogelstein 2019), it is increasingly likely that any subsequent 'technological moment' must adopt a new kind of social responsibility alongside any awe-inspiring 'futures' it purports to embody. 
Etic Lab's on-going Underpass Festival project will undertake public consultations and workshops to ask local communities about what matters in their experience with emerging technology, its role in the public arena and, by extension, social inclusion. For many, the promise of 'new' technology is already understandably entwined with popular culture and the attitudes and expectations of a 'big release'. The Lab's approach to research and development is instead founded on addressing identifiable industrial problems that can find grounding within independent research practices, rather than being isolated to the Quality Assurance departments of large tech firms. We will act alongside these groups to workshop instances where better use cases of public AR can lead to improvements in public art display, urban development and community building.

$A R$ and VR feel destined to be judged entirely on their immediate capabilities (Weis 2018) and at present, the visual nature of those capabilities is at its most prevalent in the context of one-off leisure activities and casual gaming (Matney 2019). It is these activities that are currently benchmarking the reception of an entire sector across a distorted scale between wealthy institutions such as museums or large galleries hosting the technology, alongside what is essentially playing a computer game in a park with friends or family. Even with the lack of dedicated hardware, AR seems burdened with addressing the issues of real-time visualisation to the same standards as VR. The Underpass Festival's motivation is to reframe that discussion around its specific potential as a more modest form of digital immersion. AR that offers the opportunity to harness the existing underused resource of public space, in locations already earmarked for functional reassessment, and for delivering flexible cultural programming in place of novelty or overreaching one-off events.

The project is working towards virtually installing a month-long festival of contemporary artworks onto the walls of the public walkways in the centre of Milton Keynes. This is a location where the architectural vision of late 60's utopian modernism coalesced into public infrastructure that remains usable, frequented, and whose scale and design already goes some way to articulating the form of an outdoor gallery space. The city itself still leans on the non-hierarchical distributed grid structure inspired by urban theorist Melvin M Webber's writings during the 1960s; AR's integration with this location is a timely embodiment of his belief that the populations of future cities, rather than solely existing inside the frameworks laid down and controlled by urban planners and designers, would instead begin to enable themselves through their use of technology to guide the way nascent environments might flourish (Webber 1963).

\section{THE STATE OF IMMERSIVE TECHNOLOGY}

While over the past 5-10 years, virtual, augmented and mixed realities have frequently been held aloft as the next step towards a future where the digital aspects of our life would merge with the environments we currently occupy. So far its executions have felt exclusive and isolating, either thematically, or in rejecting certain content in favour of instances showcasing the technology as that content itself.

Far from a feeling of developmental progress and irrespective of actual advancements, 'Virtual Reality Experiences' have become synonymous with the tropes of bowling alleys and the smell of stale popcorn. Long after the buzz from devices such as Oculus over seven years ago have dissipated, next-gen headsets now seem destined for the military (Kelly 2018), and reaction to recent developments in the sector appears to reflect the notion that immersive technology is struggling to respond to expectations (Tepper 2018). A considerable factor in this development is the overwhelming lack of democratic sentiment the stagnation of the industry now seems to indicate. The motivations of start-up communities built from the aspiration to share digital experiences have been replaced by the same dull procedures a race to market tends to prompt (Sullivan 2019).

While it's easy to pick apart the likelihood of anyone, including a Hollywood celebrity, sitting alone with a headset on to essentially watch a TV very close up (Oculus 2018), AR in particular has been caught up in marketing its own mythologised promises. There is disconnect between the aspirations of its capabilities and their availability. The expectation that when the Blade Runner future started to emerge, Joe Public would immediately be on the receiving end of floating adverts for Cola doesn't match the reality. Earlier this year, around the time of the release of a handset, Samsung debuted, with a straight face, an advertisement entitled 'The future'. An amalgamation of science fiction-inspired special effects, under the caveat "all scenarios are fictionalised and simulated", accompanied by a pithy rendition of Doris Day's Que Sera Sera. It beautifully frames crowds of people in a city park defeating a giant monster with smartphone laser arrows. The strapline for the advert - "What we create today, lets you create in the future" - an almost prophetic embodiment of the disconnect between this technology's standing and its eventual use. Far more symptomatic than merely a case of, 'it isn't quite ready yet'. Increasingly, the sector recently feels as though it's shifting away from the disturbing novelty of catching Pokémon in graveyards, towards a sense that $A R$ should tackle a prevailing narrative riddled with the wrong kind of irony (Lomas 2018). 
Integrating AR into public spaces for education, entertainment even healthcare (Umali 2019) does, of course, showcase technological innovation built to deliver remarkable experiences, but why not also seek out a more direct level of engagement? Something more subjective and achievable. The Underpass Festival project has begun to explore ways AR can focus on function, however crude, rather than waiting for the improvements in render quality that come with each new smartphone release. The corresponding research resists the lure of attempting to directly supplement already well-developed AR Platforms, systems such as Apple's AR Kit and Google's AR Core for building out the content, or even existing solutions such as Artivive (https://artivive.com/), that already explore the Visual Art space through AR overlays in their implementation. Neither does the project aim dedicate resources towards the specific technical issues surrounding occlusion or geolocation that are already being addressed neatly by other organisations such as 6Ai in Oxford (https://www.6d.ai/) and 8th Wall in Palo Alto (https://8thwall.com). It overlooks these in favour of the simple idea that AR will only improve if it is used. And specifically, that those use cases need to better relate to environments where the opportunity for study isn't hinged solely on the hardware in people's pockets but also on how best to once again bring together pockets of people.

Installations applying AR techniques in European cultural centres and museums have grown over the last few years. Several cities have developed systems for enhancing the visitor experience, while in the UK cities such as Sheffield have used AR to add value to specific pieces of tourist information (Leach et al. 2018). Artists and designers have collaborated with technical support to explore AR in their practices, in a fragmented but growing drive to create additional value. However, all are hampered by the necessity to assemble many different technologies into a coherent whole. The spread of innovation is limited by cost and inability to build upon or easily reproduce the custom experiences created; simple, functional ideas quickly get bloated by compatibility issues, app downloads and operating instructions. Those hurdles are also often secondary to the impacts of the existing state of the industries themselves. These include the ability to find suitable sites to view AR pieces or even, in the case of galleries, how previous digital solutions including the effectiveness of social platforms such as Instagram have sometimes also been detrimental to modelling or sustaining a business. A similar pattern characterises the steady growth of projects in the education sphere. In contrast to the creative industries, highly capitalised sectors such as construction have seen the rapid evolution of AR/VR systems. In these industries, the products are more specific and scalable; they address problems through one-off solutions and have found support and uptake by providing an evident return on investment.

What is often overlooked in regard to the examples above is ease, specifically the ways an audience's relationship with new digital solutions must be energised through instances where interactions have been concise and rewarding. The Lab's research over the last several years has often been conducted in relation to ideas surrounding 'meaningful interactions': where, within the context of our own work, social media practices have looked to "encourage and reify communities of interest" so that 'purpose' might be amplified and result in definable actions. This functions on the premise that the influencing principles of giving, affordance, shared-pain and bearing witness might, when incorporated into interactions and framed by conversation, become relevant in the connection between these digital communities and other technologies including mixed reality. More recently this investigates whether our modelling using social media bots can be reframed to trial the efficacy of contributing to the digital reclamation of a specific location (Hogan 2018).

With this 'claiming' in mind, AR becomes one endpoint in a wider process that must acknowledge the relevance of how a combination of several other digital technologies may eventually be required to overlay and support both it's adoption and, crucially, its overall capacity. Secondly, users who are open to accepting any shortcomings in relation to their expectations might also feel able to find satisfaction in enabling developmental contributions in a rewarding way.

The distinct test for mixed reality in activating this community of practice through "common concern [...] or passion" is dependent on whether the motivation is skewed in favour of slick technology or if a user's connection to 'place' for example, could provide an equally powerful contextual incentive.

\section{THE VALUE OF SITE AND CONTEXT}

Milton Keynes offers Etic Lab an exciting opportunity, whereby several aspects of deploying immersive technology into the public sphere find a convenient place to coalesce, not least for its potency as a community of practice in waiting. The 'New Town' has recently reached its 50th birthday, and with that milestone, in city terms at least, the beginning of its adolescence. The progressive vision for the city originally presented and since stifled through years of political change has started to emerge once more as a trendy catalyst for its 
reassessment. It's also prompted a requirement for the city to recognise and start defining the kind of 'place' it is and wants to be, as a way of sidestepping the stereotypes with which it has historically been burdened.

Central to this reassessment has been Milton Keynes' growth. Its fundamentally good infrastructure and geographical positioning between London and Birmingham have seen the business base of the city continue to spike and the population rise congruently to nearly 300,000 . This exponential growth has led to demand for more cultural and leisure activities, at the same time as a dearth of independent and local businesses due to the associated inflated real estate costs (Milton Keynes Council 2019). However, the more progressive aspects of the centre's infrastructure continually highlight an underutilised opportunity the city's transient areas.

A vast network of underpasses and walkways span the city in a way designed to alleviate the need for pedestrians to encounter traffic unless completely necessary. Many even provided prebuilt social and meeting space incorporated into its design fundamentals, for example most of the city centres walkways are flanked by low walls and planters originally designed as seating. The network is used heavily, and the volume of foot traffic they cater for during peak hours provides an audience extremely familiar with the city's efficiencies but equally hyper-aware of its shortfall in activating the space's potential for civic atmosphere.

MK Smart City and the 5G Cityfibre projects, the National Transport Catapult and even the prevalence of automated delivery robots and driverless cars have all recently embodied a commercial push inward to the centre in hopes of marrying up these audiences to the development of the pending City University. This combination has pushed forward-thinking expectations for the type of activity commercial and creative residents expect to see in Milton Keynes, and openness to engaging with emerging technologies literally greeting them on their doorstep.

With the above under consideration, the Lab has begun to highlight the city's viability as an ideal testing ground for the kind of shared immersive experiences we felt AR might better represent. It is a location whose makeup and history already aligns with theories concerning new ways to democratise public space, which are beginning to resurface, and an understanding of how to harmonise those attitudes with the visual landscaping of the city. This combination has presented Etic with a way to frame research into defining the suitability of this technology to better respond to the context of its surroundings, focused on both providing and importantly championing new sites for collective experience. At the same time, this provides a 'control' to rigorously test new solutions heading to market. These include ways in which AR might be as immersive in its execution as in its delivery, and location-based research might provide a crucial stepping-stone towards visual experiences that are not solely reliant on resolution and the promise of something sublime.

The Underpass Festival is establishing a chance to investigate the challenge of presenting culturallyrather than commercially focused use cases with all the rigorous demands of quality and experience that entails. When placed alongside casual and passive engagement opportunities and reinforced by use from the existing communities, this should remove some of the more formal and exclusive aspects of event-based AR. Replacing it with openness surrounding the formulation of a different kind of public space, one with the opportunity to reflect on what merged space and by extension its actual 'publicness' means for its users.

\section{USEFUL AUGMENTATION}

It is this act of the public claiming and reclaiming 'space' that feels so intrinsic to AR's next phase of development. It's certainly an area that speaks to both the potential and the concerns regarding a technology hinged on being able to merge the real and the digital. It is also, due to the power of an aware consumer, a cynical justification for why so much of the current activity seems so much more isolating and closed off than expected.

In addition to the infrastructure already found in Milton Keynes, the artistic heritage of the city has aligned itself with the idea of integrating the visual. The design of many of its public spaces features public artworks incorporated throughout its grid communities. Initial informal consultation with artists and local groups received enthusiastic responses to developing approaches to virtually install and experience more works into the fabric of their city. People are aware of the monopoly on common spaces in the city centre, and it quickly became apparent that consensus already leant towards how to utilise the underused public areas better. The 'iconic' underpasses and walkways again stood out. For residents, there's a sense that the underpasses already form an important visual system for the city, and the idea that they should be 'used more' feels almost a given.

Not only have the underpasses therefore quickly established themselves as an opportunity to develop the kinds of inclusive and immersive narratives we feel are required to engage multiple users at the level needed to conduct a reliable 
study, but also restate that most users feel respectful enough of them to want to support rather than disrupt how they function. The town market, rows of striped canvas and galvanised shuttering represents a divisive embodiment of ways that the filling of these under-spaces can provoke a polarising reaction: indelicate handling of previous use of these spaces sparked controversy, however the lighter footprint of AR offers to offset those immediate concerns.

Putting aesthetics aside, the market does reflect the way that enabling communities to shape how they use these transitional public spaces themselves has already proved successful. For us, the scaffolding of a solution that recognises the entire suite of engagements between the city and its public are what require building upon. We will take an approach that leads from communal mapping and designation of the sites and surfaces the festival will occupy, through to the installation, programming and placement of digital works. The project will also endeavour to address the secondary consequences of any new virtual activity and even how it may become a micro resource in locations that have so far only ever served their primary functions. For us, its potency will only ever emerge from a solution that offers one user the ability to map and 'claim' a space to present an experience, alongside addressing other users' needs to share that experience or a third user to monetise, gift or craft it.

Low-fi tech solutions such as Google cardboard, and the Nintendo Labo VR kit (Muncy 2019) have already recognised how a 'full process' type approach can resonate with users as access to the workings and preparations empowers them to share and engage with the act of using in of itself. It's of little coincidence then, that in these instances ease of use and affordability have simultaneously pushed further demand and development. Our focus is to develop similarly accessible innovations for The Underpass Festival. As Google said in 2015, "The dead-simple and dirt-cheap VR headset seemed like a lark last year, a silly 20-percent time hack, but it has clearly become a real project": it's sold a million Cardboard-based devices (Pierce 2015).

These kinds of approaches represent a path to delivering an immersive experience relieved of the constraints formal events impose: stand here, download this, look at that. They can instead focus on how to place a more flexible experience in front of an audience and emphasise the purpose of the experience in relation to the location and circumstances of the user. By accepting this alternative as an appealing proposition, a logistical necessity then emerges. Could that kind of experience also be delivered cheaply and easily using the hardware/software commonly available?

Web-based AR platforms already provide a range of exciting opportunities and bring forward the ability to site content in a way that can immediately speak to a user's connection to a project. Marrying that to localisation through a mobile browser would be a suggestive next step in curating content in a discoverable way. That combination quickly becomes a route to curating cultural programming less contingent on markers, QR codes and reference imagery. Another pivotal part of democratising the technology lies in enabling audiences to understand and participate in the full range of AR's uses and interactions, feeding back into a project's own deployment in a way that affords the user respectful engagements proportional to their input. Context is crucial for this, and the festival itself furnishes the study a beneficial frame.

Building in openness with users can be a useful way to respond to public awareness of the data AR will inevitably generate. Outside of the context of 'one-off events,' these issues will only be amplified. It also provides room to foreground the issues themselves, including how the visual nature of evolving hardware will continue to expose the user to new considerations. Physical safety concerns of personal injury due to crime or distraction and unchecked high fidelity solutions leaving users open to digital manipulation should all be able to inform project feedback while the capacity of the technology remains limited.

\section{THE UNDERPASS FESTIVAL, PREPARING FOR IMMEDIACY OVER FIDELITY}

We aim to develop an approach that will enable artists and anyone with a smartphone to help map, plot and upload images to public spaces. The festival will be a culmination of the features our research and fieldwork develops, to curate and install a range of works throughout the underpass network and address limitations, alongside our own and stakeholder aspirations.

Initial developments will explore localisation and mapping in conjunction with webGL based systems for content deployment. In addition, the team are investigating visual positioning systems to supplement the limitations of GPS and potential provisions using image localisation and neural network object detection for a portion of the project. Deep learning techniques will aim to bolster instances where mapping AR using markers or distinct image object techniques perform poorly, as in urban environments where the background is too simple to track, or the query image so similar or 
close to the object that it cannot recognise key features to map against. We also see unexplored and underexplored opportunities for AR development surrounding the issues of occlusion and rendering qualities linked to web-based imagery and have reached out to partners to address such problems with our in-house team in the context of the festival.

We are simultaneously researching the production of a more accessible alternative for organisations of all sizes looking to develop immersive experiences, at a standard consistent enough to promote wider adoption. Adaptable systems, capable of being repurposed to an audience quickly and affordably, and a core framework allowing users to place an object into virtual space in a way that feels deliberate and seamless, will offer real value; doing so in a way that affords the audience the choice of when and how to experience it could be equally crucial.

This is also where artistic approaches to using the technology may have influence. We expect that our research in collaboration with artistic needs, based on the actual use of and engagement with the limits of the technology, will lead to new developments. For example, existing artist AR projects using smartphones apply a variety of artistic methods and strategies for overcoming or working with technological limitations, often by focusing on a specific element to drive audience engagement.

Projects such as theatre company The Only Animal's 2nd Story production in Vancouver's Blood Alley used narrative, in the form of stories collected from the local community, to drive the audience engagement rather than overblown heroic HD imagery. The visual elements were simple films shot with actors in the location, viewable by holding a smartphone up to the space (https://www.theonlyanimal.com/show/2nd-story).

Digital\&Dead (2017), an app produced by artists Rachel McRae and Sarah Derat, enables the viewer to walk around an AR monument as it morphs between different shapes, mimicking the minimal geometry of gravestones, tombs, monuments and monolithic server/data farms. The viewer simultaneously experiences a multi-layered sound composition using field recordings from London cemeteries, text from social media memorials and conversations with chatbots. (https://cargocollective.com/digitalanddead). Very few artists appear to use off-the-shelf AR apps for their works; Molly Soda's AR book project, Shared, is one of these (Tiffany 2017); it uses open source app HPReveal (previously Aurasma) to add moving overlays or short videos that supplement the printed artwork (https://www.hpreveal.com/). As these projects show, AR artworks don't need to be
HD to be effective. As with Hito Steyerl's 'poor image', low-fi AR offers a more popular and egalitarian way for artists to develop and share this technology:

\begin{abstract}
"The poor image is a copy in motion. Its quality is bad, its resolution substandard. As it accelerates, it deteriorates. It is a ghost of an image, a preview, a thumbnail, an errant idea, an itinerant image distributed for free, squeezed through slow digital connections, compressed, reproduced, ripped, remixed, as well as copied and pasted into other channels of distribution." (Steyerl 2012)
\end{abstract}

The poor image supports a more democratic '(re)distribution of the sensible' in Rancierian terms (Ranciere 2004), in opening out the production of AR's aesthetico-political regime from corporates to artists and communities. Low-fi AR may in fact align more with Steyerl's description of Juan García Espinosa's 'Imperfect Cinema' in Cuba, which "merges art with life and science, blurring the distinction between consumer and producer, audience and author" (Steyerl 2012).

Augmented Reality does not necessarily need to be primarily visual, as evidenced by the Ambient Literature locative media project, a two-year collaboration between UWE Bristol, Bath Spa University and the University of Birmingham (https://research.ambientlit.com/):

\begin{abstract}
"The term 'ambient literature' refers to writings that are in some way contextualized to and/or by a place in which you experience them. Allowing a location to contour and affect content, and maybe vice-versa... A new project based in the West Country of England explores the possibilities of writing that's informed not only by a sense of location, but also by the affordances of smartphones, and what they can bring to storytelling." (Horne 2016)
\end{abstract}

The piece works through GPS location and userinteraction; the story you're reading knows where you are, and can respond to your input. Similarly, we envisage that narrative drive will need to become a huge component of the festival. Although not explicitly intended to link into an overriding narrative, the impetus for repeated engagements underpass after underpass will need to form a substantial part of the design philosophy we hope to present to our audience.

\section{VISUAL DEMOCRATISATION AND THE OZ EFFECT}

In all the above cases, the technology was not attempting to be the centre of the show - it was there to enable an experience. As suggested by recent research into the uses of low and high fidelity simulation in medical training, low fidelity 
simulations can enable better engagement with the actual content, as participants are not solely passive observers awed by HD media (Bligh and Bleakley 2006; http://www.transtechresearch.net/research/researchprojects/simulation-lab/). This is supported by Etic Lab's recent research into the use of bot technology, where, as others have also observed, the more successful interactions occurred not with the slickest attempts to mimic human behaviour, but when the 'bot' openly divulged what it was and why it was there (Wooley et al. 2016, Savage et al. 2016). There may also be something about the nonhuman nature of the technological interaction that encourages participation. In a recent study focusing on building mental resilience among youth, users who knowingly communicated with a chatbot named Wysa had a 45 percent reduction in depression, and medication adherence rose by 10 times. Patients preferred to speak with a bot, often covering taboo topics (Siwicki 2018). This demystification of the technology is part of what we call the Wizard of Oz effect, giving power back into the hands of citizens through revealing that the 'man behind the curtain' is not an all-powerful being.

The culmination of Etic Lab's social media bot research saw us install a 'political bot' into a recent exhibition at the V\&A museum. It embodied characteristics we'd encountered and the benchmarks that the more successful bot interactions generated during our research, often when the bot itself openly divulged what it was, and why it was interacting with others rather than mimicking a human. However, inside the trappings of a museum and in the context of its 'performance' visitors consistently stood in front of and reacted to its presentation. They "invoked their knowledge of what it was capable of from what they knew of political technology [...] of how our politics has been affected by Social Media manipulation and demanded of a few lines of code far more than it was technically capable of." It's those additional lines of code that resonate; its audience already had a measure of their expectations, a colleague highlighted how the technology we'd used, although billed as emerging, was butting up against a user's criteria for judging something they, "fundamentally don't believe in".

For $A R$ and the literal overlapping of 'real' and 'virtual', this tension of belief could be amplified further, as a sense of balance falls between wanting to see both the otherworldly projection that promises so much and remain aware of the workings of how it operates. An argument could also be formulated that speaks to the difference between authentic and inauthentic voices. Or what we might call the ethics of a thing - that is, in the sense of a thing being true to its nature; the bot not trying to be more than a bot, a virtual overlay focusing first on being just that, rather than a magical spectacle in glorious HD. That awareness of the 'state of the art', and a subsequent request to engage with and influence the shortfalls of that 'state', is the first step towards a more democratic approach.

\section{CONCLUSION}

We believe that AR development needs to stem from engagement initially disconnected from the direct application of the technology itself, instead focusing on testing its uses in a more open and cumulative way. Rather than building on a particular solution or retreating to solve a problem users may be comfortable shrugging off, it is pertinent that adaptation of existing tech is channelled into more extensive use cases to put new ideas and workarounds straight into the hands of a user group. In conjunction, location-specific test cases present an opportunity to disconnect the technology from its trappings and make use of audience-centred contexts to promote broader levels of 'on-the-ground' buy-in and expand the overall scope of any trials. The on-going Underpass Festival project aims to package this up and in doing so deliver a framework where not only execution is tested, but also where peripheral issues can enter the discussions around the AR field in a more long-format and democratic manner.

\section{REFERENCES}

6D (2019) 6D.ai https://www.6d.ai/ (retrieved 17 March 2019).

8th Wall (2019) Augmented Reality https://8thwall.com/index.html (retrieved 17 March 2019).

Barrington, T. (2018) Introduction to Digital Fingerprinting. Etic Lab (retrieved 22 February 2019).

Bligh, J., Bleakley, A., 2006. Distributing menus to hungry learners: can learning by simulation become simulation of learning? Medical Teacher 28, 606-613.

Hogan, A. (2018) Real Friends and Meaningful Interactions. Etic Lab (retrieved 26 February 2019).

Horne, A. (2016) Writing in Place: An "Ambient Literature" Project in the UK. Publishing Perspectives.

https://publishingperspectives.com/2016/07/ambien t-literature-launch/ (retrieved 17 March 2019). 
Kelly, M. (2018) Microsoft secures $\$ 480$ million HoloLens contract from US Army, The Verge. https://www.theverge.com/2018/11/28/18116939/mi crosoft-army-hololens-480-million-contract-magicleap (retrieved 17 March 2019).

Leach, M., Maddock, S., Hadley, D., Butterworth, C., Moreland, J., Dean, G., Mackinder, R., Pach, K., Bax, N., Mckone, M., Fleetwood, D., 2018. Recreating Sheffield's Medieval Castle In Situ using Outdoor Augmented Reality.

Lomas, N. (2018) Enterprise AR is an opportunity to 'do well by doing good,' says General Catalyst, TechCrunch.

https://techcrunch.com/2018/11/30/enterprise-ar-isan-opportunity-to-do-well-by-doing-good-saysgeneral-catalyst/ (retrieved 17 March 2019).

Matney, L. (2019) Niantic reportedly raising \$200M at $\$ 3.9 \mathrm{~B}$ valuation. TechCrunch (retrieved 27 February 2019).

Milton Keynes Council (2019) Ambitious Growth http://www.investmiltonkeynes.co.uk/growth (retrieved 17 March 2019).

Muncy, J. (2019) Nintendo Labo Gets a Cheap VR Kit. Wired (retrieved 11 February 2019).

Oculus (2018) See it in VR feat. Wiz Khalifa, Adam Levine, Jonah Hill, Leslie Jones, and Awkwafina | Oculus Go.

https://www.youtube.com/watch?v=v4eTJlbJYK4 (retrieved 17 March 2019).

Peres, Nicholas and Knight (2019) Simulation Lab (TAaCT), Transtechnology Research. http://www.trans-

techresearch.net/research/research-

projects/simulation-lab/ (retrieved 17 March 2019).

Pierce, D. (2015) Google Cardboard Is VR's Gateway Drug, WIRED.

https://www.wired.com/2015/05/try-googlecardboard/ (retrieved 17 March 2019).

Rancière, J. (2004) The politics of aesthetics. Continuum, London.

Savage, S. (2016) Botifesto - How to think about Bots, Computational Propaganda Project. https://comprop.oii.ox.ac.uk/research/publicscholarship/botifesto-how-to-think-about-bots/ (retrieved 17 March 2019).
Sergiu (n.d.) \#bringArtToLife, Artivive. https://artivive.com/ (retrieved 17 March 2019).

Siwicki, B. (2018) Next-gen telehealth: Al, chatbots, genomics and sensors that advance population health, Healthcare IT News. https://www.healthcareitnews.com/news/next-gentelehealth-ai-chatbots-genomics-and-sensorsadvance-population-health (retrieved 17 March 2019).

Steyerl, H. and Berardi, F. (2012) Hito Steyerl: The Wretched of the Screen. E-Flux, New York.

Sullivan, M. (2019) How the iPhone's next 3D camera signals phase two in the AR race, Fast Company.

https://www.fastcompany.com/90311285/appleiphone-next-3d-camera-signals-phase-two-in-thear-race (retrieved 17 March 2019).

Tepper, F. (2018) Hands-on with Snapchat's mediocre, crashy AR art, TechCrunch. https://techcrunch.com/2017/10/03/hands-on-with\begin{tabular}{lll}
\hline snapchats-mediocre-crashy-ar-art/ & (retrieved 17
\end{tabular} March 2019).

Tiffany, K. (2017) How to put internet art in a book, The Verge.

https://www.theverge.com/2017/10/1/16360410/mol ly-soda-interview-shared-digital-art-book-sarasutterlin (retrieved 17 March 2019).

Umali, T. (2019) VR and AR study aims to treat chronic pain, OpenGov Asia. (retrieved 18 February 2019).

Vogelstein, F. (2019) Facebook's Sloppy DataSharing Deals Might $\mathrm{Be}$ Criminal, WIRED. https://www.wired.com/story/facebooks-sloppydata-sharing-deals-might-be-criminal/ (retrieved (retrieved 17 March 2019).

Weis, S. (2018) Your AR App Sucks - OR - The Current Sad State of Augmented Reality, Packet39. https://packet39.com/blog/2018/03/14/ar-appsucks-current-sad-state-augmented-reality/ (retrieved 17 March 2019).

Wooley, S., Boyd, D., Broussard, M. and Made (2016) How to Think about Bots, Motherboard Vice. https://motherboard.vice.com/en us/article/qkzpdm /how-to-think-about-bots (retrieved 17 March 2019). 